\title{
CASE REPORT ON PHENYTOIN-INDUCED IATROGENIC GINGIVAL HYPERPLASIA
}

\author{
LAKSHMI NARASIMHA GUNTURU*
}

Department of Pharmacy Practice, Annamacharya College of Pharmacy, Rajampeta, Andhra Pradesh, India. Email: gunturunarasimha007@gmail.com

Received: 15 June 2020, Revised and Accepted: 15 July 2020

\section{ABSTRACT}

Phenytoin is a diphenylhydantoin which is mostly used in the treatment of epilepsies and arrhythmias. Chronic usage of phenytoin leads to a number of undesirable effects. Most of the adverse effects associated with phenytoin are hirsutism, gingival hyperplasia, osteomalacia, cleft lip, and hypoplastic phalanges. Gingival hyperplasia is an increase in the number of cells or an increase in the size of gingiva is observed due to a defect in collagen metabolism. Here, we report a case of a 20 -year-old male patient who was diagnosed with gingival hyperplasia due to the prolonged use of phenytoin for 3 months. The patient's condition was improved after the withdrawal of phenytoin and other antiepileptic drugs were recommended for his treatment.

Keywords: Phenytoin, Gingival hyperplasia, Antiepileptic, Collagen metabolism.

(C) 2020 The Authors. Published by Innovare Academic Sciences Pvt Ltd. This is an open access article under the CC BY license (http://creativecommons. org/licenses/by/4. 0/) DOI: http://dx.doi.org/10.22159/ajpcr.2020.v13i10.38761

\section{INTRODUCTION}

Phenytoin is a drug of choice to treat generalized tonic-clonic seizures. The first report of gingival overgrowth associated with the chronic use of phenytoin was reported in 1939 by Kimball [1]. Gingival overgrowth occurs as a side effect of some systemic medications and it is now well known that phenytoin is one such agent. The incidence rate of phenytoin-induced gingiva hyperplasia ranges from $3 \%$ to $93 \%$, but $50 \%$ of patients on long-term therapy tend to develop gingival overgrowth. This drug-induced overgrowth is noticed initially in the papillary region and also involves the margins and gingival attachments. The color of infected gums ranges from pink to deep bluish-red depending on the amount of inflammation and leads to bleeding. The observation of gum hyperplasia is seen in 2-3 months and takes 12-18 months to attain its maximum severity [2]. This condition is mainly due to the accumulation of collagen fibers due to the defect in collagen metabolism [3]. This case report spotlights the anticonvulsant drug phenytoin-related adverse effect.

\section{CASE REPORT}

A 20-year-old male was admitted to Government General Hospital, Kadapa, with complaints of seizures which are generalized tonic-clonic lasting for $10 \mathrm{~min}$ and loss of the history of consciousness during the episodes. He had a history of epilepsy for 5 years and using antiepileptic drugs. However, recently from the past 3 months, he is taking the phenytoin $100 \mathrm{mg}$ tablets twice a day. During his admission after a clear examination, it was found that the patient developed a gingival overgrowth on his teeth and physician dechallenged phenytoin. The condition was diagnosed as drug-induced gingival hyperplasia (Fig. 1). Laboratory investigations include hemoglobin ( $\mathrm{Hb})-11.5 \mathrm{gm} / \mathrm{dl}$, total count (TC) - 13,000 cells $/ \mathrm{mm}^{3}$, random blood sugar (RBS) - $102 \mathrm{mg} /$ $\mathrm{dl}$, and urea $-17 \mathrm{mg} / \mathrm{dl}$. Magnetic resonance imaging (MRI) of the brain reveals mild gliotic changes and diffuses cerebellar atrophy. Clinical history reveals that seizures with cerebrovascular accident.

\section{Outcome and follow-up}

After suspecting the condition, the patient was advised to stop phenytoin and treated the phenytoin toxicity by prescribing folic acid tablets $500 \mathrm{mg}$ once a day and prescribed other drugs such as Tab. levetiracetam $500 \mathrm{mg}$ twice a day and Tab. sodium valproate $200 \mathrm{mg}$ twice a day to treat the epileptic condition. After 1 week of treatment with folic acid tablets, the patient showed significant improvement in his condition and was discharged.

\section{DISCUSSION}

Gingival overgrowth was observed after the patient started taking the phenytoin treatment. Then, after the withdrawal of the phenytoin gingival overgrowth was slowly normalized and the patient is prescribed with new drugs to treat epilepsy. In many literature evidence, it was observed that phenytoin was the main causative agent for gingival overgrowth [4]. Usually, the overgrowth takes 2-3 months for appearing and takes 12-18 months for reaching the maximum overgrowth [5]. This is the same in our case report that the patient is using the drug for 3 months. This toxicity is considered a dose-dependent manner and can be labeled as a type-A class of adverse effect. Mild phenytoin toxicity can be treated symptomatically and can be reversible. Delay in discontinuing of phenytoin leads to reach the gingival overgrowth to its maximum level and the patient should opt for gingivectomy a type of surgical procedure [6]. Degradation of collagen fibers, especially type I

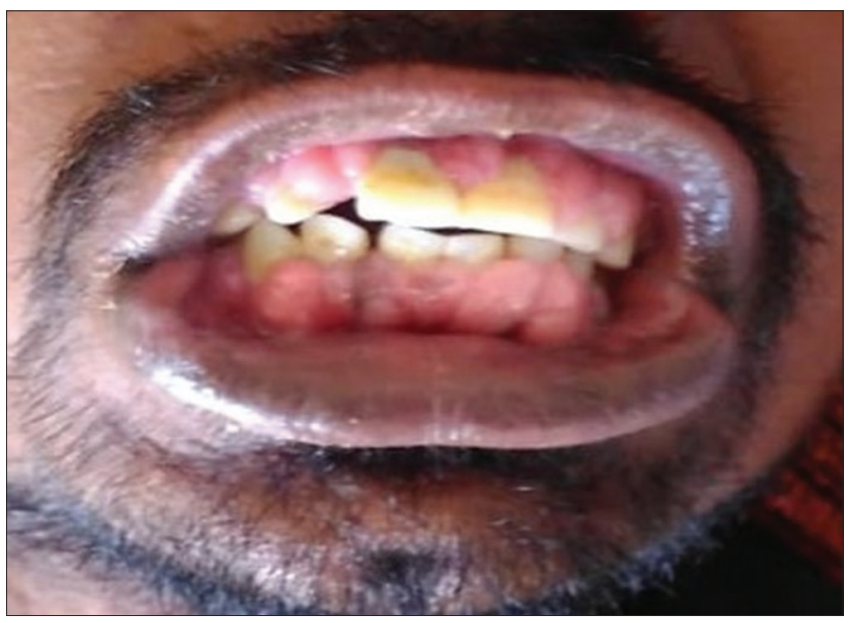

Fig. 1: Revealing gingival overgrowth 
collagen, resulting in the excess accumulation of collagen fibers in gums and causes gingival hyperplasia [7]

\section{CONCLUSION}

Adverse drug reactions are needed to be monitored and are managed in general wards to establish successful treatment and to reduce the unwanted effects. This can be successfully achieved by providing proper patient counseling to patients regarding their medications and early withdrawal of the causative agent to prevent the progression of the reaction.

\section{ACKNOWLEDGMENT}

None.

\section{AUTHORS' CONTRIBUTIONS}

Mr. Lakshmi Narasimha Gunturu was involved in the data collection, organizing of data, preparation, reviewing, and editing of the manuscript.

\section{CONFLICTS OF INTEREST}

The author declares no conflicts of interest.

\section{AUTHORS' FUNDING}

Nil.

\section{PATIENT CONSENT}

Yes.

\section{ETHICAL STATEMENT}

Ethical approval was not applicable for case report in our institution.

\section{REFERENCES}

1. Mohan RP, Rastogi K, Bhushan R, Verma S. Phenytoin-induced gingival enlargement: A dental awakening for patients with epilepsy. BMJ Case Rep 2013;2013:bcr2013008679.

2. Chacko LN, Abraham S. Phenytoin-induced gingival enlargement. BMJ Case Rep 2014;2014:bcr2014204670.

3. Kataoka M, Kido J, Shinohara Y, Nagata T. Drug-induced gingival overgrowth-a review. Biol Pharm Bull 2005;28:1817-21.

4. Angelopoulos AP. Diphenylhydantoin gingival hyperplasia. A clinicopathological review. 1. Incidence, clinical features and histopathology. Dent J 1975;41:103-6.

5. Hassell TM, Burtner AP, McNeal D, Smith RG. Oral problems and genetic aspects of individuals with epilepsy. Periodontol 2000 1994;6:68-78

6. Butler RT, Kalkwarf KL, Kaldahl WB. Drug-induced gingival hyperplasia: Phenytoin, cyclosporine, and nifedipine. J Am Dent Assoc 1987;114:56-60.

7. Correa JD, Queiroz-Junior CM, Costa JE, Teixeira AL, Silva TA. Phenytoin-induced gingival overgrowth: A review of the molecular, immune, and inflammatory features. ISRN Dent 2011;2011:497850. 